\title{
STUDY OF MULTIELEMENTAL CONCENTRATIONS AND NANO-MICRO STRUCTURAL MORPHOLOGY IN MYRTACEAE FAMILY MEDICINAL PLANTS BY FIELD EMISSION SCANNING ELECTRON MICROSCOPE-ENERGY DISPERSIVE X-RAY SPECTROSCOPY METHOD
}

\author{
TEERTHE SS, KERUR BR
}

Department of Physics, Gulbarga University, Kalaburagi - 585 106, Karnataka, India. Email: stp.santosh4@gmail.com

Received: 11 August 2018, Revised and Accepted: 12 November 2018

\begin{abstract}
Objective: The essential multielemental analysis was carried out in nano- and microscale surface morphology of two useful selected species of Myrtaceae family medicinal plants such as Eucalyptus and Guava using "field emission scanning electron microscope"-"energy dispersive X-ray spectroscopy" (FESEM-EDS). To understand the elemental analysis of medicinal plant used in Bidar, Gulbarga/Kalaburagi and Yadgir districts of the Northeast Karnataka region.
\end{abstract}

Methods: In the present investigation, Myrtaceae family's medicinal plants selected. The analysis of the samples were thorough nano-micro photograph obtained by using FESEM and specific weight percent of elemental concentration analyzed by EDX/EDS.

Results: The elemental concentrations such as $\mathrm{C}, \mathrm{O}$, magnesium, $\mathrm{Al}, \mathrm{Si}, \mathrm{S}, \mathrm{Cl}, \mathrm{K}, \mathrm{Ca}, \mathrm{Mn}, \mathrm{Fe}, \mathrm{Cu}$, and $\mathrm{Zn}$ were estimated in all the collected medicinal plants and found to be within the World Health Organization (WHO's) recommended values. FESEM morphology indicates that fine plane irregularly shaped particles, with size an average diameter $200 \mathrm{~nm}-1 \mu \mathrm{m}$, are found in both plants.

Conclusion: The Indian Traditional Medicinal Plants have been used as a potential source for general and therapeutic medicinal purposes, including as a home remedy, Ayurvedic, and herbal drugs for the treatment of different types of human diseases. The WHO established maximum permissible limits for the consumption of major, minor, and trace elements to ensure the safe uses of medicinal plants as a drug material so as to cure the diseases. The present investigation suggests that the collected medicinal plants have good alignments of secondary metabolites, functional groups, and intake of trace elements, which are useful for treatment and preparation of new Ayurvedic, herbal, and pharmaceutical drug, pellets of very small size for alignment of different diseases.

Keyword: Elements, Field emission scanning electron microscope-energy dispersive X-ray spectroscopy method, Medicinal plants, Northeast Karnataka, Permissible limits, World Health Organization.

(C) 2019 The Authors. Published by Innovare Academic Sciences Pvt Ltd. This is an open access article under the CC BY license (http://creativecommons. org/licenses/by/4. 0/) DOI: http://dx.doi.org/10.22159/ajpcr.2019.v12i2.29054

\section{INTRODUCTION}

The medicinal plants are the natural resources of the environment, which play an important role in the traditional medicine system and recommended as home remedies [1,2]. The knowledge of traditional medicinal plant medicine system has been known throughout the worldwide from ancient history [3,4]. The Indian Traditional Medicinal Plants were increased, widely and successfully developed during the period 2500-500 BC, with different indigenous systems of medicine such as Siddha, Herbal, and Unani, and also learnt by the time how to process and extract the curative properties from the plants further our ancestors uses to develop the processed product in a large scale, this information is available in Vedas and other scriptures [5]. Nearly 4 million medicinal plant species are available in India, among them only $50 \%$ of plants have been investigated as useful medicinal plants [6]. Trace, major, minor, and heavy elements play vital functions in medicinal plants as well as in the human body for the biological activity of a healthy person $[7,8]$. It is very important to investigate baseline information of the type of elemental contents available in the medicinal plants of a particular area/region, in view of the World Health Organization (WHO's) permissible limits $[9,10]$. Further, the WHO and Department of Ayurveda, Yoga and Naturopathy, Unani, Siddha, and Homoeopathy (AYUSH) within the Ministry of Health and Family Welfare focused on the implementation of regulations and improvement of standards in the areas of quality control and standard procedures for the production of medicinal plant drugs. The availability of raw material for research and development, education/training of professionals, and a wider outreach are needed with regard to these traditional medical systems [11-13]. According to theWHO, about $75-80 \%$ of the world's population depends on medicinal plant-based drugs for their primary health care, and also in India, $60-65 \%$ of peoples were relies on folk, traditional, herbal, and Ayurvedic-based medicinal plant treatment for curing different types of diseases $[14,15]$. Keeping in view of the above points, the present study deals with the elemental analysis and nano-micromorphological activity is carried out by selecting Myrtaceae family medicinal plants, namely Eucalyptus and Guava collected from different places of Bidar, Gulbarga/Kalaburagi, and Yadgir districts of Northeast Karnataka (Hyderabad, Karnataka) regions using field emission scanning electron microscope-energy dispersive X-ray spectroscopy (FESEM-EDX) method. The instrument model number in the present setup is a Zeiss ultra 55 FE-SEM EDX instruments had $1 \mathrm{~nm}$ scanning resolution with oxford $10 \mathrm{~mm}$ detector for X-ray analysis and mapping, through a non-destructive technique/ method adopted [16-18].

\section{METHODS}

\section{Collection of medicinal plants}

The images of Myrtaceae family medicinal plants such as Eucalyptus and Guava, respectively, collected from Kalabragi are shown in Fig. 1. Fresh and mature leaf samples (each of $1 \mathrm{~kg}$ samples) were collected from different places of Bidar, Gulbarga/Kalaburagi, and Yadgir District of Northeast Karnataka (Hyderabad, Karnataka) region for analysis purposes. 
Study area

The Northeast Karnataka (Hyderabad, Karnataka) region covers about $30 \%$ of the Karnataka and $50 \%$ of the North Karnataka region, a large number of different kinds of ores are available, and large-scale mining factories are running in this region, which covers elements such as manganese, iron, gold, and uranium; further, large-scale cement factories and thermal power plant are running in this region apart from the above. Study area latitude ranges from $14^{\circ} 10^{\prime}$ to $18^{\circ} 45^{\prime}$ North and longitudes range from $74^{\circ} 10^{\prime}$ to $77^{\circ} 45^{\prime}$ East, respectively, which spans a geographical area of $44138 \mathrm{~km}^{2}$ which covers six districts. The present study covers districts such as Bidar, Gulbarga/Kalaburagi, and Yadgir. Here, Bidar and Gulbarga/Kalaburagi fall in the Deccan plateau region. The soil type of Bidar is red black, Gulbarga/ Kalaburagi soil is black and medium black, whereas Yadgir district soil shows pink, red and black soils depending upon the region are naturally available.

\section{Sample preparation}

The collected leaves of plant samples were washed with a distilled water to remove clay, sand, and dust; the cleaned samples were dried in the airtight laboratory at room temperature for 30 days. The dried leaves of the plants were mechanically powdered using a mixer grinder and finally sheaved with a mesh of size $355 \mu \mathrm{m}$ to get a fine power and then stored in an airtight container. $10 \mathrm{mg}$ of fine powder was taken and prepared a pallet of $1 \mathrm{~cm}^{2}$ disks, and the sample was coated with $15 \mathrm{~nm}$ thick gold layers for contact purposes and these samples were kept for about $30 \mathrm{~min}$ one at a time subjected for elemental analysis.

\section{Data analysis}

The FESEM creates images by raster scanning over it with a high-energy beam of electrons of any sample surface. The incident electron will interaction with the atoms of the sample in turn which emits the photons from the analysis of emitted photos signals the sample information about surface topography, composition and other properties like electrical and mechanical etc. The field emission sources also called a cold cathode field emitter cross-over diameter $10 \mathrm{~nm}$ and a resolution of about $2 \mathrm{~nm}$ at 1 $\mathrm{keV}$ and about $1 \mathrm{~nm}$ at $15 \mathrm{keV}$, respectively. Therefore, the FESEM is a very useful high-resolution tool for surface imaging in the field of nanomaterial science. The technique is non-destructive and has a detectable sensitivity of $>0.1 \%$ for elements heavier than C. EDS works by detecting X-rays that are produced by a sample placed in an electron beam. The electron beam excites the atoms in the sample that subsequently produces X-rays to discharge the excess energy. The energy of emitted K or L X-rays from the

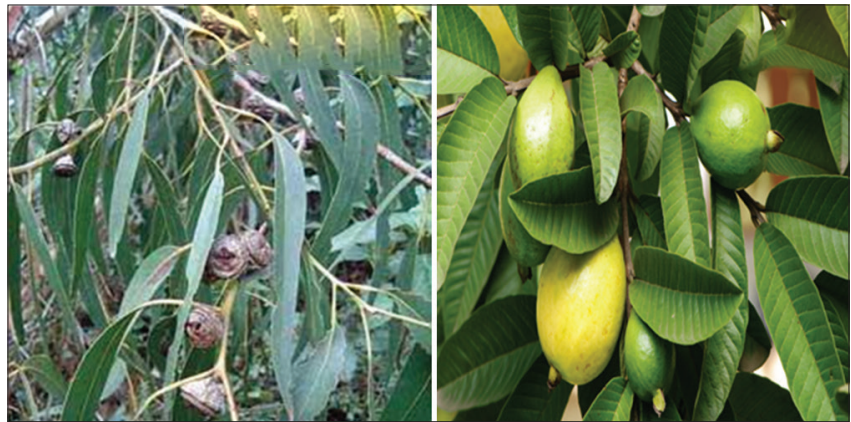

Fig. 1: Images of Eucalyptus oblique and Guava medicinal plants sample are the characteristic peaks corresponding to different elements present in the sample. The increase in the peak x-ray energy corresponds to as many as different elements present in the sample. The intensity of the peak gives information of the percentage of same element present in the sample. Since the electron beam can be precisely controlled, EDX spectra can be collected from a specific area or point/particle in the sample, giving specific analysis of a few cubic microns of material. Alternatively, the beam can sweep over a selected area of the sample to identify the elements present in that region.

\section{RESULTS AND DISCUSSION}

Table 1 represents elements in the first column and plant code in the first row along with WHO/Food and Agriculture Organization (FAO) permissible limits presented at the last row of Table 1 . The coarse grain size of medicinal plants was found to be in between $200 \mathrm{~nm}$ and $1 \mu \mathrm{m}$, and the surface morphology of the Myrtaceae family having a planar rectangular surface was found in Eucalyptus plant and anomocytic stomata with spherules structure was found in Guava medicinal plant. From Table 1, it is shown that carbon and oxygen are then found to be higher content in all two plants, the essential element, such as calcium (Ca) which lies in range $0.63-1.99 \%$ and plays an important role for intermediary and intermediate metabolism of minerals in bones and teeth to become stronger. Similarly, magnesium (Mg) found to be in the range between $0.25 \%$ and $0.78 \%$, it is an important element which helps to control and maintain the insulin level in blood, and it is a supplementary element to the calcium. The other important element potassium $(\mathrm{K})$ lies in the range from $0.52 \%$ to $1.215 \%$; if the level of potassium element is maintained by persons, then chances of getting heart attack are very much minimized. Similarly, the remaining elements such as $\mathrm{Al}, \mathrm{Si}, \mathrm{S}, \mathrm{Cl}, \mathrm{Cr}, \mathrm{Mn}, \mathrm{Fe}, \mathrm{Cu}$, and $\mathrm{Zn}$ were found to be below the permissible limits of WHO/FAO as shown in Table 1. Iron, copper, and zinc are the supplementary elements which help the formation of hemoglobin content in blood since DNA and oxygen carry part of blood cells. The present study focused on toxic elements present in the medicinal plants, but there is availability found to be very less quantity as low as permissible limits given by the WHO. Hence, in the

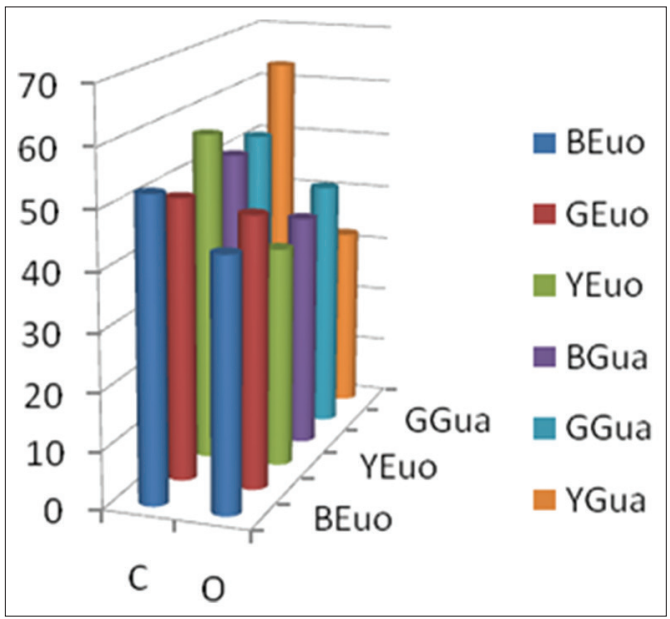

Fig. 2: Carbon and oxygen variation

Table 1: Elemental content and WHO/FAO limits studied in medicinal plants (in wt \%)

\begin{tabular}{|c|c|c|c|c|c|c|c|c|c|c|c|c|c|c|}
\hline Code & C & $\mathbf{0}$ & Mg & Al & $\mathbf{S i}$ & $\mathbf{S}$ & $\mathrm{Cl}$ & $\mathbf{K}$ & $\mathrm{Ca}$ & $\mathrm{Cr}$ & Mn & $\mathbf{F e}$ & $\mathrm{Cu}$ & Zn \\
\hline BEuo & 52.26 & 43.59 & 0.56 & 0.25 & 0.12 & 0.09 & 0.56 & 0.52 & 0.63 & 0.13 & 0.61 & 0.31 & 0.12 & 0.23 \\
\hline GEuo & 48.89 & 47.08 & 0.76 & 0.12 & 0.11 & 0.14 & 0.41 & 0.76 & 0.65 & 0.11 & 0.39 & 0.23 & 0.15 & 0.17 \\
\hline YEuo & 57.1 & 38.31 & 0.35 & 0.22 & 0.24 & 0.45 & 0.57 & 1.15 & 0.9 & 0.09 & 0.13 & 0.06 & 0.13 & 0.19 \\
\hline BGua & 51.09 & 40.75 & 0.28 & 0.84 & 1.4 & 0.5 & 0.5 & 1.21 & 1.99 & 0.08 & 0.18 & 0.89 & 0.09 & 0.16 \\
\hline GGua & 52.11 & 43.62 & 0.25 & 0.07 & 0.08 & 0.05 & 0.3 & 1 & 1.95 & 0.08 & 0.18 & 0.12 & 0.06 & 0.12 \\
\hline YGua & 63.21 & 32.11 & 0.78 & 0.49 & 0.41 & 0.61 & 0.15 & 0.53 & 1.11 & 0.09 & 0.12 & 0.13 & 0.14 & 0.11 \\
\hline Limits WHO & 65.0 & 40.0 & 35.00 & 12.6 & $<1.0$ & $<1.0$ & $<1.0$ & 70.01 & 36.61 & 2.0 & 2.0 & 20.0 & 3.0 & 27.4 \\
\hline
\end{tabular}

WHO: World Health Organization/FAO: Food and Agriculture Organization, Mg: Magnesium 
present investigation, the toxic elements are not playing any role in the studied medicinal plants.

The carbon and oxygen are the building block elements of the livings things, and Figs. 2 and 3 show variations of carbon and oxygen content along with other major, minor, and trace elements in both medicinal plants which are clearly visible. These elements play an important role in photosynthesis process, and also the biological process of the medicinal plant. The carbon and oxygen concentrations level were found highest in both the regions of medicinal plants.

The surface morphology and energy spectra of medicinal plants are shown in 's. 4 and 5, it is electron image of two medicinal plant leaves, and the size of the particles lies between $1 \mu \mathrm{m}$ and $200 \mathrm{~nm}$ in the energy range from $1 \mathrm{KeV}$ to $12 \mathrm{KeV}$ of $\mathrm{X}$-ray energies emitted from $\mathrm{K}$ and $\mathrm{L}$ shell of the elements present in the plants of the Eucalyptus and Guava (Fig. 4)

The morphology study shows that surfaces of these plants are amorphous in nature with particle size lying between $1 \mu \mathrm{m}$ and

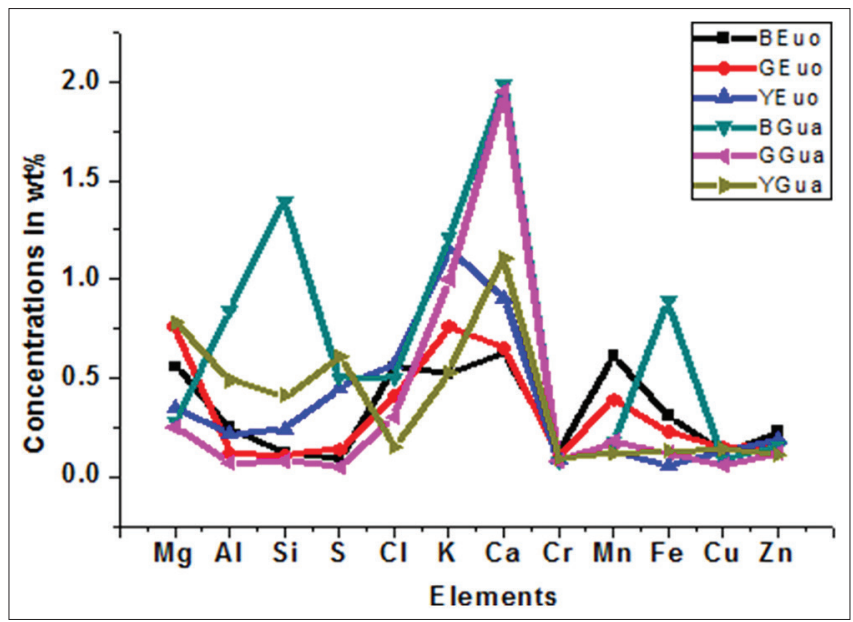

Fig. 3: Elemental concentration variation
$200 \mathrm{~nm}$ which confirms that the biological sample reactions also take place within this order only, and hence, investigation of new drugs may be initiated using the above medicinal plants since these medicinal plants are heavily used by the local medical practitioners. The studied 14 elemental concentrations in two Myrtaceae family leaves of medicinal plants are found comparatively less than the permissible limits of the WHO. It is very helpful to further chemical constituents and pharmacological study, but these plant samples were used as medicine for different aliment in respective region's peoples and also used as raw materials of new Ayurvedic drug preparations for the treatment of fever, cold, head pain, dengue, joint pain, diabetes, cancer, snake bit, chicken pox, etc. Our daily consumable of the above samples which keeps our body resistive for the cold, fever, cough, etc. as mentioned above.

\section{CONCLUSION}

The original quantitative elemental concentration of Eucalyptus oblique and Guava medicinal plant leaf samples was obtained in this study. From the present results, species of Myrtaceae family shows that Guava sample contains higher concentration of different elements as compared to the Eucalyptus samples in all three districts. Further, from the FESEM analysis, the surface morphology is amorphous and semicrystalline in nature with $200 \mathrm{~nm}$ grain size for the plant. The analysis reveals that the surface morphology with grain size associated element plays an important role in medicating the diseases at the earliest. The analyzed elemental concentrations of $\mathrm{C}, \mathrm{O}, \mathrm{Mg}, \mathrm{Al}, \mathrm{Si}, \mathrm{S}, \mathrm{Cl}, \mathrm{K}, \mathrm{Ca}, \mathrm{Cr}, \mathrm{Mn}$, $\mathrm{Fe}, \mathrm{Cu}$, and $\mathrm{Zn}$, are below the permissible limits WHO/FAO.

The present work data information may be helpful for the photochemical study and preparation of a nano size pellet, syrups, and drugs for different treatments of humans. The effect of nano size particle drug sample is under further study. This may helpful to synthesis a new Ayurveda which can be used for the control various disease after oral treatment. From the medicinal plant drugs, it is very useful and needful to cure the diseases such as cancer, stomach problem, and muscular problems and makes the body physiologically stronger against multidrug resistance human pathogen, and the profile of elements mainly depends on geographical reproduction of water, soil, and physiological changes of environment.

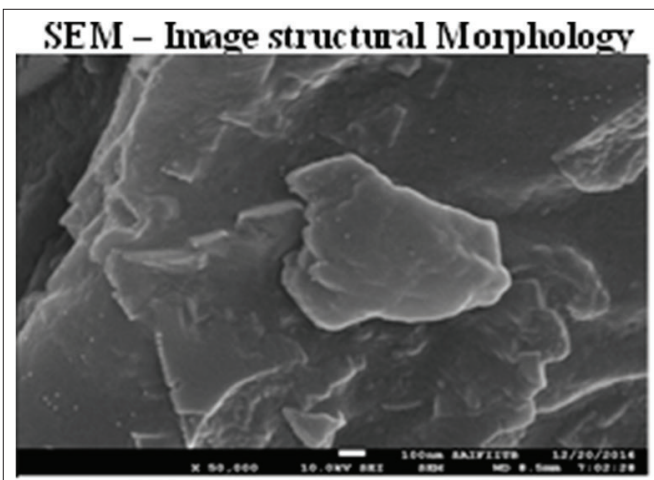

SEM - Image structural Morphology
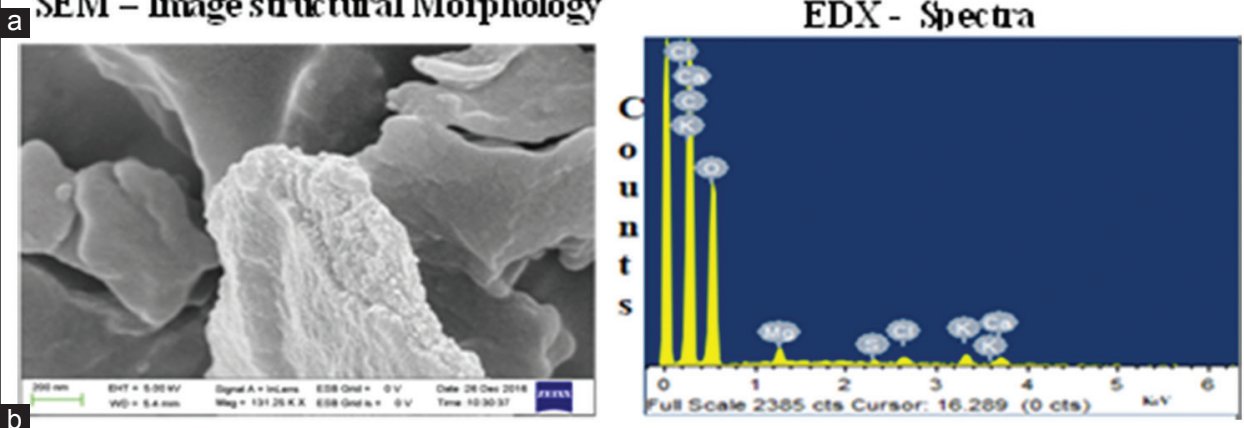

Fig. 4: Structural morphology and energy spectra. (a) Plant name: Eucalyptus oblique, (b) Plant name: Guava 


\section{AUTHORS' CONTRIBUTIONS}

S S Teerthe completed full-length manuscript by analysis the data and literature survey and B R Kerur corrected and guided for preparation of the manuscript.

\section{CONFLICTS OF INTEREST}

Authors declared no conflicts of interest.

\section{REFERENCES}

1. Swargiary A, Nath P, Basumatary B, Brahma D. Phytochemical, antioxidant, and trace element analysis of anthelmintic plants of NorthEast India. Int J Pharm Pharm Sci 2017;9:228-32

2. Pednekar PA, Raman B. Estimation of variation in the elemental contents of methanolic soxhlet leaf extract of Ampelocissus latifolia (Roxb.) planch by ICP-AES technique. Int J Pharm Pharm Sci 2013;5:938-41.

3. Pandey MM, Rastogi S, Rawat AK. Indian traditional ayurvedic system of medicine and nutritional supplementation. Evid Based Complement Alternat Med 2013;2013:1-12.

4. Muruganantham S, Anbalagan G, Ramamurthy N. FT-IR and SEMEDS comparative analysis of medicinal plants, Eclipta alba Hassk and Eclipta prostrata Linn. Rom J Biophys 2009;19:285-94.

5. Bamola N, Verma P, Negi C. A review on some traditional medicinal plants. Int J Life Sci Sci Res 2018;4:1550-6.

6. Street RA. Heavy metals in medicinal plant products-an African perspective. S Afr J Bot 2012;82:67-74

7. Devi RK. Major and trace elements in medicinal plants. $3^{\text {rd }}$ indo-global summit and expo on health care. Health Care Curr Rev 2015;3:95.

8. Shirin K, Imad S, Shafiq S, Fatima K. Determination of major and trace elements in the indigenous medicinal plant Withania somnifera and their possible correlation with therapeutic activity. J Saudi Chem Soc 2010;14:97-100.

9. Brima EI. Toxic elements in different medicinal plants and the impact on human health. Int J Environ Res Public Health 2017;14:1-9.

10. Ganesan A, Marichamy K, Taghamariappan J. Development of medicinal plants sector in India-an empirical study. Int J Eng Technol Manage Appl Sci 2016;4:82-8.

11. Pulok K, Mukherjee M, Kumar VV. An overview on the development in regulation and control of medicinal and aromatic plants in the Indian system of medicine. Bol Latinoam Caribe Plantas Med Aromát 2017;6:129-36.

12. Al-Kattan MO, Khayyat SA. Antimicrobial activity and chemical analyses of oil constituents of medicinal plant Costus speciosus (Koen.). Biomed Res 2017;28:734-9.

13. Mamedov N. Medicinal plants studies: History, challenges and prospective. Med Aromat Plants 2012;1:1-2.

14. World Heath Organizations. Traditional Medicine. $56^{\text {th }}$ World Health Assembly Provisional Agenda Item 14.10: A56/19. Report by the Secretariat; 2003. p. 1-4.

15. Olowoyo JO, Okedeyi OO, Mkolo NM, Lion GN, Mdakane ST. Uptake and translocation of heavy metals by medicinal plants growing around a waste dump site in Pretoria, South Africa. S Afr J Bot 2012;78:116-21.

16. Teerthe SS, Kerur BR. Determination of Elements in Ayurvedic Medicinal Plants by AAS. AIP Conference Proceedings; 2016.

17. Teerthe S, Kerur BR. Elemental analysis of medicinal plants from North Karnataka region by AAS method. Int J Res Ayurveda Pharm 2017;8:104-8.

18. Pattar M, Teerthe S, Kerur BR. Determination of major and trace elements of traditional medicinal plants of Gulbarga region. Int Ayurvedic Med J 2017;5:4401-8. 